\title{
Rastreabilidade do Conhecimento como Mecanismo de Melhoria de Qualidade de Software
}

\author{
Fernando Corrêa de Mello Júnior ${ }^{1}$, Fabiana Costa Guedes ${ }^{1,2}$, Carlos Alberto \\ Marques Pietrobon ${ }^{1,3}$ \\ ${ }^{1}$ Pontifícia Universidade Católica de Minas Gerais - PUCMINAS \\ Belo Horizonte - MG - Brasil \\ ${ }^{2}$ FUNCESI - Fundação Comunitária de Ensino Superior de Itabira - Itabira - MG - \\ Brasil \\ ${ }^{3}$ UFOP - Universidade Federal de Ouro Preto - Ouro Preto - MG - Brasil. \\ fernandocmjunioreterra.com.br, fabiana.costaguedes@gmail.com, \\ capietro@pucminas.br
}

\begin{abstract}
The software developers manipulates a wide variety of knowledge during the software development process. This manipulation takes place in all activities. An appropriate use of this knowledge promote the improvement of the software quality production and increases the experience gained by the software developer. Therefore, this study is a proposal to capture and to recovery of the knowledge related to the software development process, based on the goal-oriented models, lexical and requirements traceability.
\end{abstract}

Resumo. Os desenvolvedores de software manipulam uma grande variedade de conhecimento durante o processo de desenvolvimento de um software. Essa manipulação ocorre em todas as atividades. A manipulação adequada desse conhecimento auxilia na produção de software de maior qualidade e agiliza o ganho de experiência do desenvolvedor. Portanto, o objetivo deste estudo é uma proposta para capturar e recuperar conhecimento relativo ao desenvolvimento de software baseada na modelagem de metas, léxico e rastreabilidade de requisitos.

\section{Introdução}

Entre os diversos fatores relacionados à obtenção de um processo de software e de um produto final de qualidade está a manipulação do conhecimento. Segundo Natali e Falbo (2003), esta manipulação é um importante recurso utilizado pelas organizações afim de promoverem o aprendizado dos desenvolvedores. $\mathrm{O}$ conhecimento adquirido e armazenado é reusado para melhorar as atividades e as decisões necessárias para a execução do projeto corrente e de outros futuros. Para se trabalhar com conhecimento, duas situações devem ser tratadas: a transmissão do conhecimento entre o desenvolvedor e o usuário e a geração e distribuição do conhecimento entre os desenvolvedores.

A primeira situação está diretamente relacionada com a determinação das reais necessidades do usuário e tem como entraves o fato dos envolvidos, que pertencem a universos diferentes, se fazerem entender e devido à mutabilidade dos requisitos. 
A segunda situação está relacionada com o entendimento do problema pela equipe desenvolvedora, que tem que trabalhar cooperativamente, compartilhando e gerando conhecimento. Segundo Togneri et al. (2004), os problemas relativos à transmissão do conhecimento entre os integrantes da equipe de desenvolvimento podem resultar em uma série de dificuldades, tais como: perda do conhecimento sobre a aplicação em desenvolvimento, podendo ficar restrita à pessoa e não à empresa; escassez de conhecimento sobre o domínio da aplicação, o que dificulta a especificação dos requisitos; dificuldade em localizar as informações sobre as soluções adotadas no desenvolvimento e dificuldade na reutilização do conhecimento entre projetos semelhantes.

No desenvolvimento, entender como as diversas partes geradas em diversos momentos do processo se relacionam é uma maneira de se abordar o conhecimento. Assim, precisamos de um mecanismo de rastreabilidade para registrar os relacionamentos entre as partes, de modo a melhorar a qualidade do processo do desenvolvimento e do produto final.

Dentro desse contexto, este artigo apresenta uma abordagem para a manipulação do conhecimento utilizando-se da rastreabilidade baseada em léxico. Essa rastreabilidade inicia-se com a modelagem de metas/requisitos e permite o registro de todas as atividades e artefatos produzidos pela equipe de desenvolvimento. É fornecido, para a manipulação do conhecimento, um formato de apresentação e recuperação dos registros dos léxicos relacionados às atividades, artefatos e domínio. A união da rastreabilidade baseada em léxico e o formato da apresentação formam a rastreabilidade do conhecimento.

O artigo está organizado da seguinte forma: na seção 2 discute-se a rastreabilidade em relação ao conhecimento; na seção 3 apresenta-se o problema a ser tratado; na seção 4 apresenta-se a solução adotada; na seção 5 apresenta-se a conclusão obtida a partir da aplicação da solução no desenvolvimento e manutenção de projetos de pequeno e médio porte em uma pequena empresa de desenvolvimento de software.

\section{Rastreabilidade}

A rastreabilidade é uma parte relevante do processo de desenvolvimento e deve ser considerada pelas empresas, que queiram melhorar a qualidade do produto final e melhorarem seu nível de maturidade nos processos (MPS/BR,2006). De acordo com os modelos CMMI e MPS/BR, a rastreabilidade deve ser bidirecional, de modo a:

- Permitir o acompanhamento da vida do produto tanto do mais alto nível para o mais baixo nível, quanto ao contrário;

- Mostrar o relacionamento com outras entidades, ou seja, relacionar os artefatos com as atividades que o produzem ou consomem.

Gotel e Finkelstein (1994) trabalham a rastreabilidade fundamentada nos seguintes itens: contribuição, contribuidor, estrutura social, relação de contribuição, estrutura da contribuição e rastreamento baseado em contribuição. Ramesh e Jarke (2001) apresentam um meta modelo que divide a rastreabilidade em três dimensões: as fontes, os interessados e os objetos de produto ou do processo. Toranzo, Castro e Mello (2002) classificam a rastreabilidade em quatro níveis: ambiental, organizacional, 
gerencial e desenvolvimento. Quanto aos relacionamentos existentes entre os elementos, o autor aponta os seguintes: satisfação, recurso, responsabilidade, representação, alocada e agregação.

A visão da rastreabilidade, deste trabalho, está baseada no léxico, no formato da sua apresentação e na classificação relacionada à origem do conhecimento, ou seja, no domínio, nas atividades e artefatos do processo e na gestão dessas atividades.

Segundo Ramesh (2002), a rastreabilidade é um dos componentes chaves para a transmissão do conhecimento. A rastreabilidade deve permitir o acompanhamento do requisito durante todo o seu processo de transformação no produto de software. Essa transformação é mapeada a partir da criação e manutenção dos relacionamentos entre objetos e pessoas. Os objetos estão relacionados com o domínio e os artefatos produzidos na construção de um software. E as pessoas estão relacionadas com as atividades do processo e gestão, que são realizadas para a identificação do domínio e a geração dos artefatos, os quais se transformam em um software.

Os relacionamentos formam a rastreabilidade, que ajuda a criar, armazenar, recuperar, transferir e aplicar o conhecimento para a criação de um produto de software. Segundo Ramesh (2002), a "rastreabilidade ajuda a gerar o conhecimento explícito e tácito sobre o processo de desenvolvimento de software e suas saídas", pois, a habilidade de relacionar as fontes do conhecimento leva os envolvidos a "insights" e idéias sobre o produto que está sendo construído. E ainda facilita a colaboração, a comunicação e a criação do conhecimento entre os integrantes da equipe de desenvolvimento.

De acordo com Ramesh (2002), "o processo de conhecimento na engenharia de software é qualquer conhecimento explicito ou tácito que envolve as atividades, passos e processos envolvidos na criação de uma solução de software". Portanto, o essencial para a geração do conhecimento é a criação de uma rede de relacionamentos entre objetos/objetos, pessoas/pessoas e de relacionamentos entre objetos e pessoas. Os desenvolvedores com menor experiência se beneficiam a partir do entendimento dos relacionamentos existentes e dos registros dos desenvolvedores mais experientes sobre as soluções adotadas.

\subsection{Léxico}

O léxico é o conjunto de vocábulos de um idioma. No caso da engenharia de software, é usado para definir tanto o universo de discurso do domínio da aplicação, quanto o universo de discurso do processo de desenvolvimento de um software. O conhecimento a ser transmitido para a equipe de desenvolvimento é obtido a partir da identificação desses léxicos e dos seus relacionamentos. Esses relacionamentos formam a rastreabilidade de qualquer entrada lexical.

Uma entrada lexical pode variar o seu conceito de acordo com a sua utilização. Portanto, a compreensão do universo de discurso é realizada mais rapidamente, se os envolvidos no processo de desenvolvimento de um software utilizassem um vocabulário comum. Essa compreensão do vocabulário ajuda na transmissão do conhecimento durante a atividade de elicitação de requisitos (SILVA, LEITE E BREITMAN, 2005). 


\subsection{Metas}

Meta é o objetivo que o sistema (software + ambiente), como um todo, deve atingir na visão do usuário, ou seja, na visão do negócio no qual o produto a ser construído está inserido. Por exemplo: a meta agilizar o faturamento médico pode ser atendida através da aquisição de novos computadores e/ou através da construção do requisito integração com os Hospitais. Portanto, o foco inicial a ser trabalhado e modelado é o negócio do cliente. Esta postura permite identificar como o sistema contribui para a melhoria do processo produtivo do cliente, de modo que se possa entender o domínio no qual o software está inserido. Adotando-se esta postura, obriga-se o usuário a descrever seu negócio e suas atividades, impedindo que detalhes do software sejam discutidos em um primeiro momento (LAMSWEERDE, 2001).

A partir da identificação das metas identificam-se os requisitos do sistema. Os requisitos são suportes para que as metas sejam atendidas. A identificação das metas e requisitos é feita por meio de diversas técnicas, como entrevistas, análise de documentação e refinamento.

O refinamento é obtido utilizando-se das perguntas "como" e "por que". O "Como?" permite identificar e entender as sub-metas e os requisitos. O "Por quê?" identifica o nível superior das metas/requisitos. $\mathrm{O}$ resultado final é o modelo de metas, o qual representa a hierarquia existente entre os requisitos e as metas (LAMSWEERDE, 2001). O modelo de metas ajuda na documentação, na comunicação entre os envolvidos e na compreensão do que tem que ser desenvolvido na atividade de elicitação de requisitos. Portanto, o conhecimento é obtido na identificação e na formação da rastreabilidade dos requisitos do usuário em relação às metas.

\section{Rastreabilidade do Conhecimento}

A figura 1 ilustra o fluxo do conhecimento durante o processo de transformação dos requisitos em um produto de software. Através dessa figura, pode-se compreender como o conhecimento obtido junto ao usuário é capturado e disseminado para que a equipe de desenvolvimento possa realizar suas atividades. São apresentados os dois pontos do conhecimento que devem ser tratados na rastreabilidade durante o desenvolvimento de um software: necessidades do usuário e do desenvolvedor.

Nota-se que as necessidades do usuário, representadas nessa figura, são obtidas como um conjunto de narrativas ${ }^{1}$ que devem ser interpretadas, compreendidas e satisfeitas pelo engenheiro de requisitos para o desenvolvimento do produto. A partir do modelo de metas, o engenheiro de requisitos transmite o conhecimento necessário para a equipe de desenvolvimento realizar suas atividades.

Após o entendimento dos requisitos, a equipe de desenvolvimento realiza atividades para a construção do software. Os produtos resultantes dessas atividades são os artefatos, os quais representam uma parte ou o todo de um produto de software. As atividades e os artefatos representam o conjunto de narrativas que caracterizam o conhecimento gerado pela equipe de desenvolvimento.

\footnotetext{
${ }^{1}$ Narrativa: a maneira de narrar; Narração; História; Narração: exposição escrita ou oral de um fato; Ato ou efeito de narrar.
} 
A equipe de desenvolvimento deve tomar decisões durante a realização das suas atividades. Essas decisões são tomadas em função do conhecimento existente e refletem-se nos artefatos produzidos. Assim, essas decisões acumuladas geram a experiência da equipe para a produção do software. Essa experiência deve ser armazenada no banco de conhecimento, baseado em léxico, para que a própria equipe possa usufruir, mais tarde, do conhecimento gerado durante o desenvolvimento. A manipulação da rastreabilidade consiste na manipulação do conhecimento gerado na produção do software. Portanto, melhorando a manipulação do conhecimento durante a execução das atividades melhora-se a qualidade do processo e do produto como um todo.

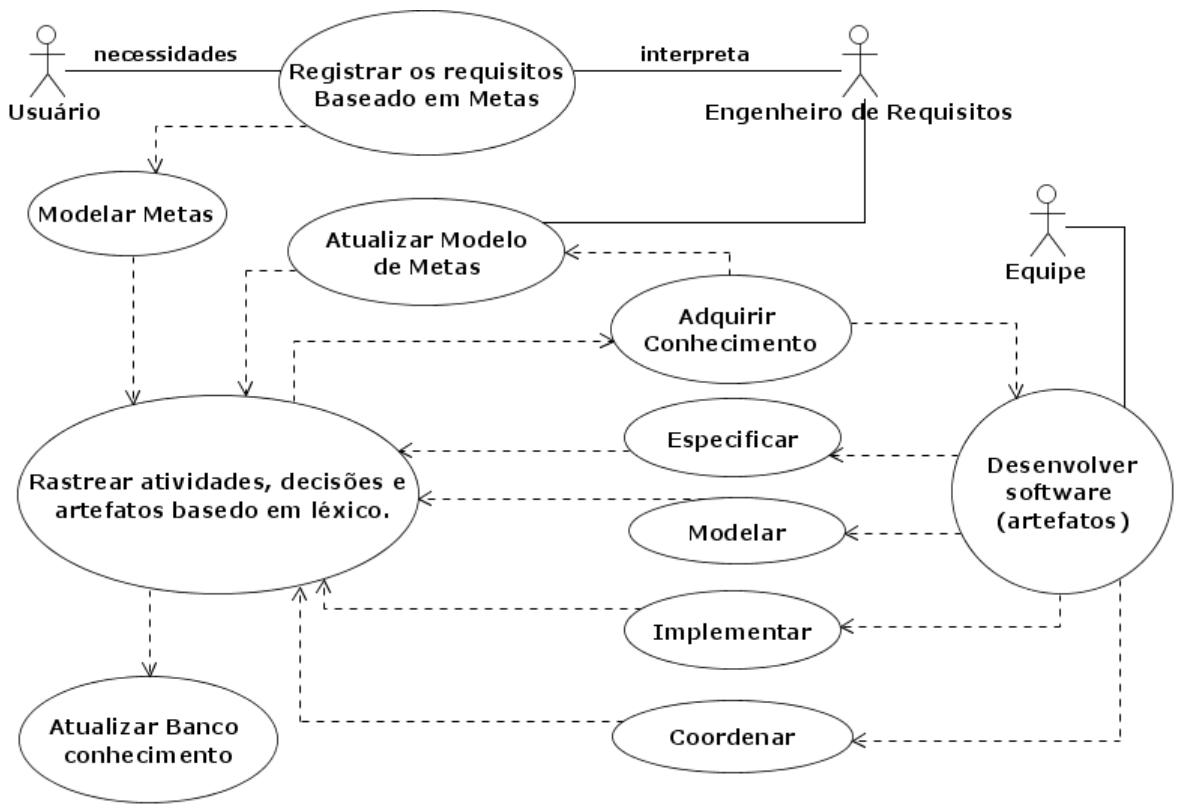

Figura 1 - Fluxo do conhecimento

\section{Rastreabilidade Baseada em Léxico}

Para manipular o conhecimento relativo ao desenvolvimento de um software, esse trabalho parte das seguintes premissas:

- Todos os elementos existentes no desenvolvimento do software, tais como: processo, gestão, metas, requisitos, atividades e artefatos, são considerados como léxico. Por ser um léxico o elemento tem a ele associado um conceito. Esse conceito pode variar de acordo com o contexto utilizado (tipo de léxico);

- As estruturas dos relacionamentos existentes entre os léxicos formam o conhecimento a ser manipulado pela equipe de desenvolvimento.

A rastreabilidade baseada no léxico estendido corresponde à ligação entre os diversos elementos do léxico, de modo a identificar os relacionamentos entre sujeito, verbo, objeto e estado (figura 2).

O sujeito e o objeto, normalmente, são os elementos representados pelas atividades de processo e gestão e pelos artefatos produzidos. O sujeito é relacionado a outro léxico o qual atua como objeto e, esse relacionamento é obtido por meio da 
identificação do verbo que os correlaciona. Essa identificação pode ajudar na interpretação e na compreensão da rastreabilidade, uma vez que ela identifica o tipo de ação existente entre os dois elementos. O relacionamento entre os léxicos pode ser complementado com informações existentes no estado. $\mathrm{O}$ estado é utilizado para melhorar o entendimento e a compreensão da rastreabilidade entre o sujeito e o objeto.

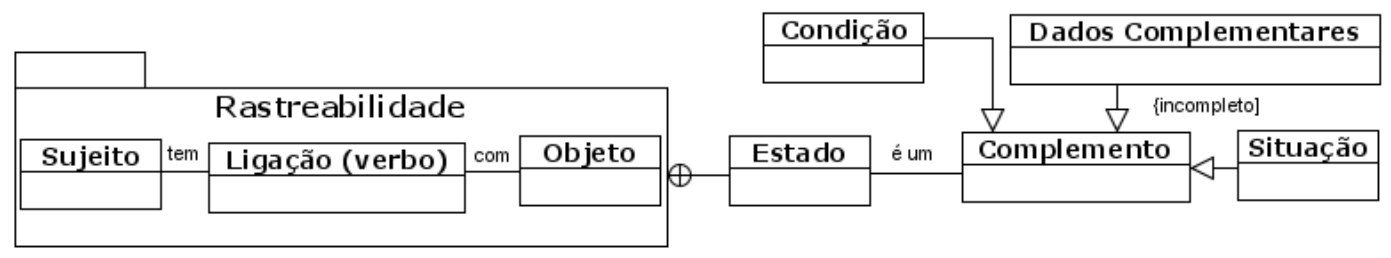

Figura 2 - Rastreabilidade baseada no Léxico Estendido

O complemento pode ser especializado em situação, dados complementares e condição. Na figura 2, a especialização está representada como incompleta, pois existe a possibilidade de inclusão de novas especializações, que podem ser importantes na manipulação do conhecimento. O mais importante é que se possa criar as condições necessárias para a manipulação do conhecimento do processo de software, respeitando as características da empresa e das pessoas envolvidas nesse processo.

A vantagem da rastreabilidade baseada em léxico está na forma da sua apresentação, pois ela se assemelha:

- Ao formato natural da linguagem escrita de comunicação utilizada pelas pessoas;

- Ao formato das técnicas de trabalho, desenvolvido pelo engenheiro de software. $\mathrm{O}$ engenheiro de software, através das técnicas de modelagem, relaciona os elementos existentes no domínio do problema com os existentes no domínio da solução e, ainda, relaciona os elementos dentro do próprio domínio do problema e dentro do domínio da solução. $\mathrm{O}$ engenheiro de software busca com esses relacionamentos construir um projeto de um produto de software.

\subsection{Apresentação da Rastreabilidade}

A utilização da rastreabilidade, como fonte de conhecimento, está relacionada diretamente com a forma da sua apresentação, ou seja, sua visualização. É importante que a apresentação da rastreabilidade tenha uma navegação fácil e rápida, de forma a obter o conhecimento necessário. Dentro do propósito do Projeto Discovery ${ }^{2}$ (PIETROBON, 2007), este trabalho se propõe a apresentar uma abordagem que facilite esta visualização. Segundo Nascimento e Ferreira (2005), os objetivos da visualização são "ampliar nossas atividades cognitivas, melhorando o entendimento e aproveitamento do que é exposto e levando à aquisição e solidificação do conhecimento".

\footnotetext{
${ }^{2}$ O Projeto Discovery tem por objetivo estudar como visualizar a informação e o conhecimento sobre o processo de desenvolvimento de software.
} 
Neste trabalho optou-se por trabalhar a rastreabilidade em forma hierárquica, ou seja, visualizá-la em forma de árvore, devido à sua simplicidade, facilidade de implementação e de ser de domínio público. Não necessitando, assim, efetuar um treinamento, visto que, as pessoas estão acostumadas com seus conceitos e forma de navegação. Cada nó da árvore representa o sujeito e/ou objeto. A relação existente entre o sujeito e objeto corresponde ao verbo. Cada nó pode ser representado por um ícone, com o objetivo de facilitar a identificação do léxico. Dessa forma, acredita-se que a visualização proposta poderá atingir os dois atributos apresentados por Mackinlay citado por Nascimento e Ferreira (2005, p.10): expressividade (mostrar os dados de interesse do usuário) e efetividade (facilidade de compreender os dados apresentados).

A visualização da apresentação da rastreabilidade, neste trabalho, busca facilitar a aquisição do conhecimento por parte do usuário, incorporando os modelos de rastreabilidade apresentados por Gotel e Finkelstein (1994), Ramesh e Jarke (2001) e Toranzo, Castro e Mello (2002). Essa visualização é dividida em dois itens: visão e formação.

A visão tem como objetivo separar o conhecimento de acordo com a sua origem. Assim, a formação da rastreabilidade, está dividida nas seguintes visões: técnica, processo e gestão. Durante a análise da rastreabilidade, essas visões podem ser trabalhadas pelo usuário em um formato de combinação, ou seja, o usuário pode selecionar uma ou mais visões para serem analisadas em conjunto. Assim, os elementos da formação da rastreabilidade podem ser vistos de modo agrupado ou individualmente.

Essa combinação é importante para aliar a rastreabilidade aos objetivos que o usuário tem na aquisição do conhecimento específico à sua função ${ }^{3}$ exercida no projeto. Essa possibilidade de combinação na pesquisa, também, diminui o conjunto de léxicos a serem apresentados no resultado da pesquisa. $\mathrm{O}$ controle dessas combinações de visões e, por conseqüência, do número de léxicos apresentados simultaneamente, pode ajudar no processo de raciocínio relativo ao conhecimento.

Quanto à formação da apresentação, essa foi subdividida em: composição, formatação, impacto e tempo, para qualquer elemento rastreável. A formação busca incorporar os principais relacionamentos existentes entre os elementos dentro da rastreabilidade. A análise da rastreabilidade desses elementos consiste na fonte de informação que o usuário necessita para a busca do conhecimento, capaz de agilizar o seu processo de adquirir experiência e de tomada de decisão. Eles são abordados nas seções seguintes.

\subsubsection{Composição}

A composição representa os relacionamentos existentes diretamente entre os léxicos, que expressam que um léxico sujeito é constituído por vários léxicos objetos. Esses relacionamentos e esses léxicos objetos fazem parte diretamente da constituição do léxico sujeito, seja a rastreabilidade anterior à sua transformação (pré-requisito), seja a rastreabilidade posterior à sua transformação (pós-requisito) (GOTEL E FINKELSTEIN, 1994).

\footnotetext{
${ }^{3}$ Função: A função corresponde ao papel que o usuário da rastreabilidade exerce no desenvolvimento do projeto. Como exemplo, podemos citar: o gestor, engenheiro de requisitos, programador.
} 
A visualização conjunta da composição, em um mesmo nível hierárquico, pode permitir ao usuário da rastreabilidade uma maior agilidade no processo de conhecer, pois são apresentados todos os elementos que constituem o item analisado.

A figura 3 exemplifica a apresentação da composição. De acordo com a figura, o requisito Gerar Fatura tem quatro composições: é narrada por, foi realizada, é formada por e foi autorizado. Essas quatro composições são representadas pelos verbos de ligação existentes entre o sujeito em análise e os objetos. No exemplo apresentado, o sujeito em análise é o Requisito - Gerar Fatura, o qual é narrado pelas histórias Selecionar Espelhos e Visualizar Valores. Para o desenvolvimento desse requisito foram necessárias as atividades de Elicitação, Modelagem, Programação e Teste. Esse desenvolvimento foi autorizado pelo Ator Fernando e é formado pela classe de interface intGerarFatura, pela classe de controle contGeracaoFatura e pelas classes entidades Fatura, Atendimento, Convênio, Espelho e Procedimento.

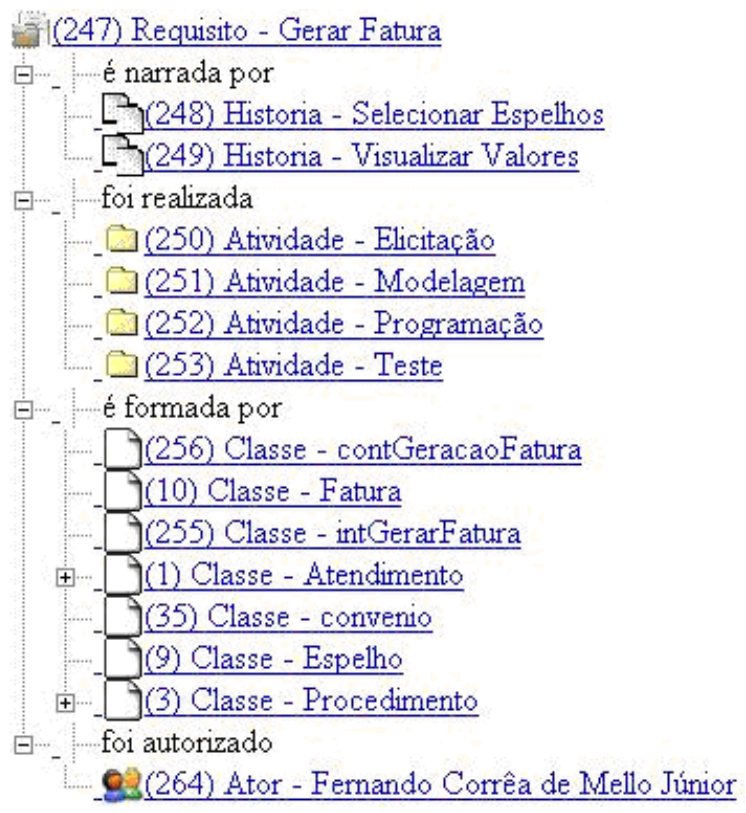

Figura 3 - Apresentação da Composição da Rastreabilidade

A composição pode variar de acordo com o tipo de léxico representado pelo léxico sujeito. Mas, normalmente é representada por questões como as listadas a seguir:

- Documentos utilizados para o seu entendimento;

- Atividades realizadas e artefatos construídos na transformação dos requisitos;

- Relação existente entre o que foi planejado e o que foi executado;

- Decisões necessárias para a execução das atividades que representam as lições aprendidas para o léxico analisado;

- Modelos produzidos que representam o léxico analisado;

- Classes utilizadas para a sua transformação em um produto de software;

- Métodos implementados nas classes; 
- Tabelas de banco de dados que mapeiam as classes entidade.

\subsubsection{Formatação}

A rastreabilidade deve ser apresentada em duas formatações simultâneas: a voz ativa e a voz passiva. A voz ativa indica a composição do artefato na hierarquia direta, indica que um léxico $L 1$ é constituído de um léxico LO. Ela representa o processo de relacionamento no formato natural, ou seja, a composição natural do léxico analisado. A voz passiva representa o processo de relacionamento inverso da composição, indica por quem o léxico analisado é constituído. A análise simultânea destas duas formatações ajuda na agilização da compreensão do elemento que está sendo rastreado.

A figura 4 apresenta a formatação da rastreabilidade simultânea na voz ativa e voz passiva. No exemplo apresentado, a História - Visualizar Valores - é formada pelas classes atendimento, espelho, intGerarFatura e Procedimento. Simultaneamente, para ajudar na compreensão do item analisado, é apresentada a voz passiva. A voz passiva indica que o sujeito História Visualizar Valores é uma narrativa do requisito Gerar Fatura.

Voz Ativa
é formada por
$-J(1)$ Classe - Atendimento
$-(9)$ Classe - Espelho
(255) Classe - intGerarFatura
(24) Classe - Procedimento

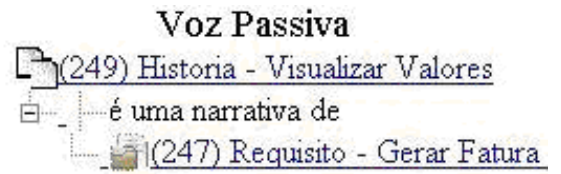

Figura 4 - Formatação da rastreabilidade na voz ativa/voz passiva

\subsubsection{Impacto}

A análise do item impacto consiste na possibilidade de se conhecer a composição de cada léxico objeto relacionado ao léxico sujeito analisado. O impacto é apresentado em forma de árvore na rastreabilidade. Essa análise permite avaliar o impacto a partir do entendimento da constituição de qual ou quais elementos podem ser afetados em uma possível mudança. Esse entendimento é obtido a partir da identificação da rastreabilidade do elemento ligado diretamente ao item analisado. Ou seja, o impacto é apresentado a partir da navegação em árvore de toda a rastreabilidade dos elementos que constituem o elemento analisado.

A figura 5 apresenta um exemplo da análise de impacto na Voz Ativa do léxico Meta-Atender bem o médico. Ela é composta pelo relacionamento é suportado por que está ligado diretamente com os requisitos Calcular Impostos, Digitar Rapidamente e Gerar o Espelho. Com a apresentação do impacto é possível navegar em cada um desses itens, verificando a sua composição. No exemplo apresentado o Requisito Digitar Rapidamente é composto pelos relacionamentos é narrada por e foi autorizado. No próximo nível de impacto, o exemplo mostra a constituição da História Digitar Rapidamente. Ela é composta pelo relacionamento é formada por. Este relacionamento está ligado às classes Atendimento e Procedimento. Assim, é possível verificar o impacto de qualquer mudança na meta Atender bem o médico. 
A apresentação do impacto também deve ser feita na Voz Passiva. Na figura 5, é apresentada uma análise da rastreabilidade de impacto de alteração da classe atendimento. No exemplo, é apresentado o possível impacto até a Meta-Atender bem o médico.

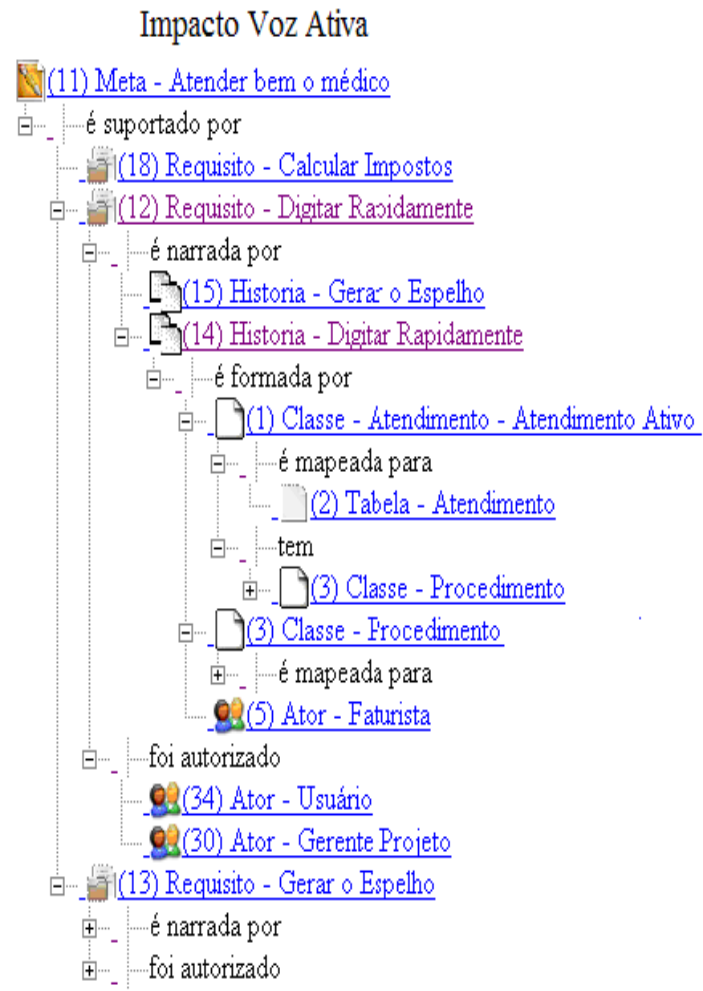

Figura 5 - Análise de Impacto na voz ativa/voz passiva

A análise de impacto indica que qualquer alteração na classe atendimento pode afetar a história Digitar Rapidamente, e que, por conseqüência, a composição pode afetar os requisitos Gerar Espelho e Digitar Rapidamente. Neste último caso, pode ainda afetar a meta Atender bem o médico.

\subsubsection{Tempo}

A rastreabilidade deve ser apresentada de forma temporal. Ela deve permitir a visão da composição, da formatação e do impacto em um determinado período de tempo. A comparação temporal da rastreabilidade pode ajudar a fortalecer o conhecimento adquirido. Esse fortalecimento ocorre através da aquisição da experiência que existe nas alterações dos léxicos e dos relacionamentos da rastreabilidade. Essas alterações ocorrem durante todo o ciclo de vida do projeto e do produto e são registradas através da manutenção dos artefatos e da atualização da base de conhecimento. A experiência é adquirida a partir do momento em que se pode comparar um léxico no tempo. Essa comparação pode ajudar a compreender a situação atual de um determinado léxico identificando as decisões tomadas no decorrer do tempo.

Toda alteração da base de conhecimento deve ser atualizada a partir de uma data de vigência. Qualquer alteração em um artefato, por exemplo, seja inclusão de um novo método, seja uma alteração de um método atual, deve ser atualizada na base de 
conhecimento da rastreabilidade com a data da alteração. Se a alteração da base for uma atualização de um léxico já existente, deve ser criado um novo registro de rastreabilidade e o registro anterior deve ter a sua data final atualizada com a data da alteração menos um dia. Dessa forma, garante-se a formação temporal da base de conhecimento.

É de suma importância ter-se a condição de navegar nas decisões de projeto em um determinado período, bem como, de promover para a gerência de alteração de requisitos a possibilidade de verificar quais foram as alterações de um determinado léxico (artefato). Essa temporalidade ajuda na rastreabilidade vertical, ou seja, na identificação das versões da base de conhecimento e na comparação entre os léxicos da mesma base.

\subsection{Processo de Formação da Rastreabilidade}

O processo de geração do conhecimento, necessário ao desenvolvimento de software, inicia-se com o planejamento das atividades que devem ser seguidas durante a confecção do software. Nessa fase, identificam-se os léxicos, relativos às atividades de gestão e do processo, e as estruturas de relacionamentos que existem entre os léxicos. As estruturas de relacionamento devem ser compostas de acordo com o contexto e a visão desejada para a gestão do conhecimento.

A execução das atividades, relacionadas com a geração dos artefatos, é a base para a transformação das necessidades do usuário em um produto executável pelo computador. O registro dessas atividades forma o conhecimento dos desenvolvedores. Esse registro é feito a partir dos léxicos e das estruturas de relacionamento proposto.

A parte final da geração do conhecimento corresponde ao registro das lições aprendidas durante todo o desenvolvimento, ou seja, as lições aprendidas na execução das atividades (gestão) e as lições aprendidas na construção de algum artefato de software.

O conhecimento, conforme é concebido neste trabalho, divide-se em:

- Conhecimento externo: corresponde à busca do conhecimento a ser desenvolvido, mediado pelo usuário;

- Conhecimento interno: corresponde ao registro de todos os elementos produzidos durante a confecção do software.

A rastreabilidade do conhecimento externo inicia-se com a modelagem de metas. O próprio modelo sugerido por Lamsweerde (2001) apresenta a rastreabilidade dos requisitos em relação às metas que o produto deve atingir. Dessa forma, cada meta ou cada requisito é considerado um léxico e o relacionamento de suporte, obtido a partir dos refinamentos, formam o conhecimento necessário ao desenvolvimento.

A rastreabilidade do conhecimento interno corresponde ao trabalho de registrar a rastreabilidade dos requisitos, modelados a partir de metas, com todas as atividades realizadas e artefatos produzidos. Essa rastreabilidade deve ser feita de modo a registrar a transformação do requisito em algo executável e registrar as decisões tomadas durante a realização das atividades. Esse registro corresponde à atualização do banco de conhecimento. 
O sucesso da manipulação do conhecimento, a partir da rastreabilidade, está na capacidade de se manter o banco de conhecimento atualizado. Esta atualização deve ocorrer no momento em que a atividade manipuladora dos léxicos estiver sendo executada. Um conhecimento gerado e não atualizado, ou atualizado fora do tempo, pode perder o sentido para uma determinada pessoa que tem a necessidade de usar o conhecimento armazenado. Nesse caso, é necessário desenvolver programas que façam a manutenção do banco de conhecimento no momento em que está sendo gerado. As atividades consideradas relevantes para a atualização do banco são:

a) Importação do modelo de metas/requisitos.

b) Análise da história: a história corresponde à necessidade do usuário relativo a um item do desenvolvimento. Nessa análise são gerados os léxicos e os relacionamentos relativos ao domínio do problema;

c) Modelagem nas ferramentas utilizadas para o desenvolvimento: o engenheiro de requisitos utiliza ferramentas para modelar o projeto. Dentre essas ferramentas pode-se citar: importação para o banco de conhecimento da estrutura do banco de dados criadas nos sistemas de gerenciamento de banco de dados; importação dos arquivos XML gerados pelas ferramentas de modelagem UML. Nesse trabalho, o modelo de classes de software foi o único utilizado para a atualização do banco de conhecimento. O modelo de classes representa, de forma estática, o domínio do problema, apresentando os léxicos que devem ser relacionados para a estruturação do conhecimento relativo ao software;

d) Cadastramento da ferramenta de rastreabilidade: os léxicos e os relacionamentos identificados durante a fase de planejamento e de execução das atividades devem ser cadastrados na ferramenta;

e) Identificação das tabelas descritivas: a partir da identificação e alteração do conteúdo das tabelas descritivas do sistema, o léxico deverá ser atualizado. As tabelas descritivas normalmente correspondem a um estado, ou a uma situação que determinadas classes podem assumir durante o seu ciclo de vida no sistema.

\subsection{Ferramenta}

A ferramenta desenvolvida neste trabalho possui dois módulos. O módulo de modelagem de metas e o módulo central para registro e análise da rastreabilidade de todas as atividades e os artefatos produzidos.

\subsubsection{Módulo de Modelagem de Metas}

A figura 6 apresenta as principais funcionalidades do módulo de modelagem de Metas. A ferramenta exporta um arquivo XML, que é importado pelo módulo de rastreabilidade. Permitindo assim, iniciar o processo de formação da rastreabilidade do conhecimento do software. Cada meta e requisito sâo considerados uma entrada lexical para o projeto no universo do discurso do domínio da aplicação.

É possível identificar o projeto (oval superior), as metas (oval intermediário) e os requisitos (retângulo). Para cada meta é possível documentar: as propriedades, as associações, os conflitos e as necessidades de refinamento. $\mathrm{Na}$ janela de propriedades das metas é possível indicar um nome e uma descrição, bem como indicar as respostas 
das perguntas como e por quê. Na janela de associação, é possível ligar uma meta ou requisito a outra meta (submeta) ou requisito, indicando a forma de contribuição, positiva $(+)$, ou negativa (-). Na janela de propriedade dos requisitos é possível indicar o nome e a descrição do mesmo. $\mathrm{O}$ modelo de metas pode ser analisado para verificar inconsistências e o resultado é apresentado na janela Análise.

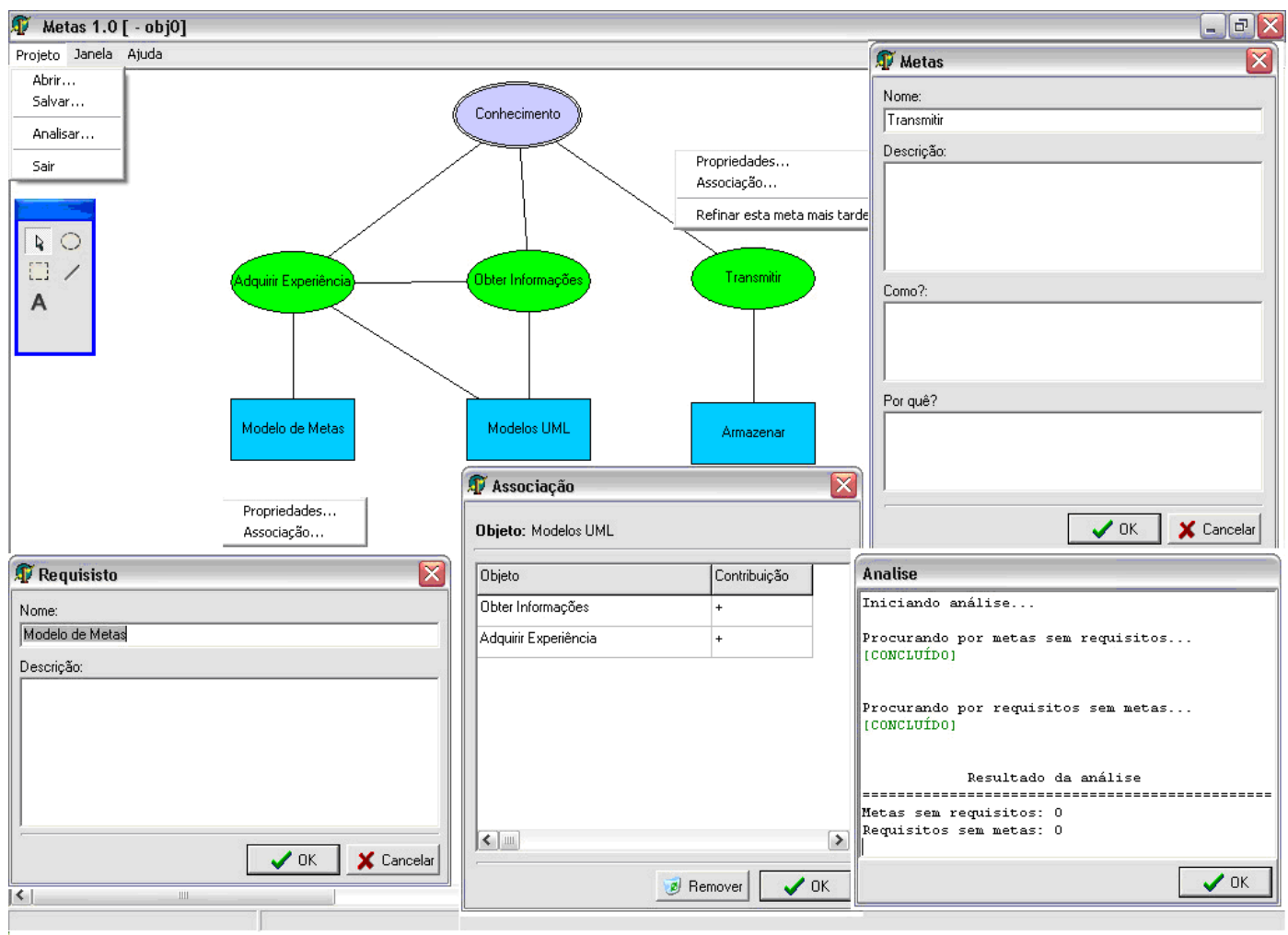

Figura 6 - Módulo de Modelagem de Metas

\subsubsection{Módulo de Analise da Rastreabilidade}

A análise da rastreabilidade tem como objetivo transmitir o conhecimento armazenado no banco de conhecimento. A interface da análise da rastreabilidade foi elaborada para que o usuário possa obter todas as informações rapidamente, garantindo, desse modo, a absorção do conhecimento. A figura 7 apresenta a interface da ferramenta para a manipulação do conhecimento. Essa interface é composta por duas partes.

A primeira parte tem por objetivo selecionar um determinado léxico, informar a data da pesquisa e a visão desejada. A seleção pode ser feita indicando o tipo de léxico e/ou a descrição do léxico. De acordo com a seleção efetuada, é apresentada uma lista de léxicos, posicionada à direita na tela. A segunda parte é dividida em Voz Ativa, Voz Passiva, Histórico de Alterações, Conceitos, Léxicos Consultados e Inf.Complementares. A pasta Voz Ativa lista a rastreabilidade da composição de forma direta e, a pasta Voz Passiva apresenta a rastreabilidade de forma inversa. A pasta Histórico de Alterações apresenta todas as alterações efetuadas para o léxico. A pasta Conceito apresenta todos os conceitos do léxico de acordo com o contexto utilizado. $\mathrm{O}$ contexto é indicado na ligação do léxico com o tipo de léxico. A pasta Léxicos 
Consultados armazena todos os léxicos consultados pelo usuário, formando uma lista seqüencial das análises já efetuadas. É possível alterar a pesquisa selecionando um dos léxicos da lista. Isso agiliza o processo de consulta e navegação, pois não interrompe o raciocínio do usuário. A interface Inf.Complementares apresenta os complementos (estados) existentes entre os léxicos em análise.

A navegação pode ser feita clicando-se em qualquer léxico das interfaces $V o z$ Ativa, Voz Passiva e Léxico Consultados. Sempre que o mouse for posicionado sobre um determinado léxico, a ferramenta descreve o seu conceito na interface Conceito.
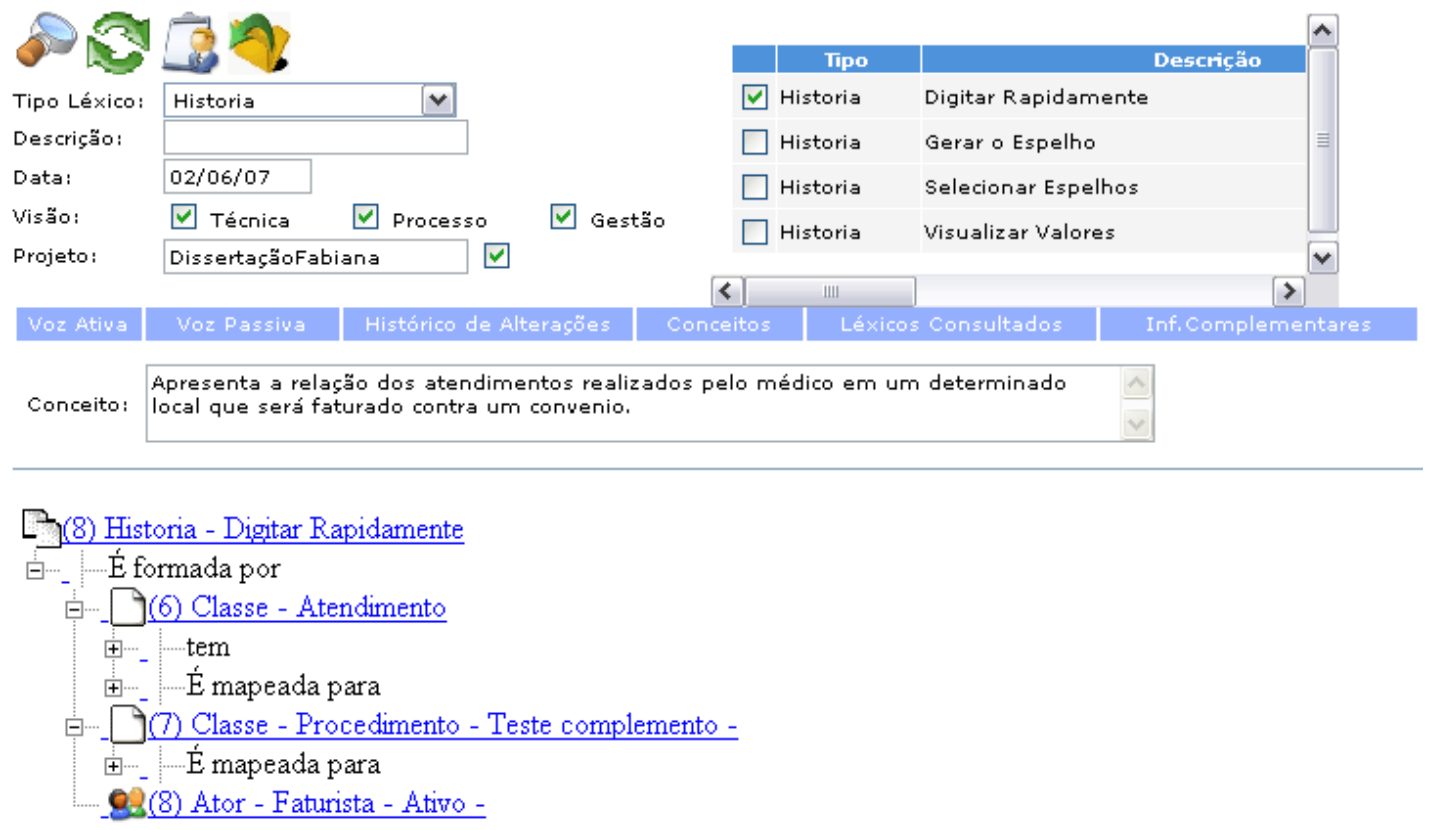

Figura 7 - Tela de Análise da Rastreabildiade

\section{Conclusão}

Este trabalho apresentou uma proposta de rastreabilidade do conhecimento. Essa rastreabilidade é apoiada pela ferramenta de modelagem de metas e pela ferramenta de rastreabilidade baseada em léxico. Diante do apresentado e das experiências utilizandose a ferramenta, chega-se à conclusão que tanto a modelagem de metas quanto a rastreabilidade baseada no léxico, ajudam na manipulação do conhecimento e na melhoria do processo de desenvolvimento. $\mathrm{O}$ modelo proposto ajudou na manipulação do conhecimento, devido aos seguintes fatores:

- A modelagem de metas mostrou-se eficiente para o entendimento das necessidades do usuário, na melhoria da comunicação entre os envolvidos e na documentação dos requisitos;

- Agilidade na análise de impacto de mudança nos produtos em desenvolvimento ou já desenvolvidos. Essa agilidade ajudou na diminuição do tempo da manutenção de software;

- Apoio na atividade de identificar o tempo e o custo de um novo projeto ou de uma alteração de um produto já existente, a partir da consulta histórica do 
registro na rastreabilidade das atividades do previsto e do realizado em relação ao custo e ao tempo.

\section{Referências}

Gotel, Orlena C. Z.; Finkelstein, Anthony C. W.; "An Analysis of the Requirements Traceability Problem; Proc. Of First International Conference on Requirements Engineering, 1994, pages 94-101".

Lamsweerde, Axel Van; "Goal-Oriented Requirements Engineering: A guided Tour. August 2001, 5th IEEE International Symposium on Requirements Engineering, Toronto, August 2001, 249-263".

MPS/BR, Melhoria de Processo de Software Brasileiro, Guia de Geral, Disponível em $<$ http://www.softex.br/mpsbr/_guias/default.asp>, acessado em 18 de novembro de 2006.

Nascimento, Hugo A D., Ferreira, Cristiane B R.; Visualização de Informações - uma Abordagem Prática, XXV Congresso da Sociedade Brasileira de Computação, XXIV JAI, Unisinos, 22 a 29 de Julho, 2005.

Natali, Ana Candida Cruz; Falbo, Ricardo de Almeida; Uma Infra-estrutura para Gerência de Conhecimento em ODE; Anais da X Sessão de Ferramentas do Simpósio Brasileiro de Engenharia de Software - SBES'2003, p.13-18, Manaus Amazonas, Outubro 2003.

Pietrobon, Carlos A. M.; Projeto Discovery, Relatório Técnico, RT 01/2007, PPGEE, 2007.

Ramesh, Balasubramaniam; Process Knowledge Management with Traceability; IEEE Computer Society Press, May/June 2002.

Ramesh, Balasubramaniam; Jarke, Matthias; Toward Reference Models for Requirements Traceability; IEEE Transactions on Software Engineering, vol. 27, número 1, January 2001.

Silva, Lyrene Fernandes; Leite, Julio César Sampaio do Prado; Silva, Breitman, Karin Koogan; C\&L: Uma Ferramenta de Apoio à Engenharia de Requisitos; Revista de Informática Teórica e Aplicada; volume XII, número 1, página 23, junho 2005

Togneri Denise F., Falbo, Ricardo A., Menezes, Crediné S., Wernesback, Bernando S., Almeida, Diogo Q; Côrtes, Marina F. Utilizando Conhecimento Organizacional no apoio à Engenharia de Requisitos Cooperativa, II Workshop de Tecnologia de Informação e Gerência de Conhecimento - SBQS'2004, Brasília, Brasil, Junho 2004.

Toranzo, Marco; Castro, Jaelson F. B.; Mello, Elton; Uma Proposta para Melhorar o Rastreamento de Requisitos; V Workshop de Engenharia de Requisitos; Valencia, Espanha, 11-12, Novembro de 2002. 